\title{
The Role of Surfactant Structure on the Development of a Sustainable and Effective Cutting Fluid for Machining Titanium Alloys
}

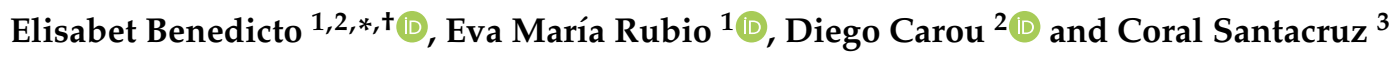 \\ 1 Department of Manufacturing Engineering, Industrial Engineering School, Universidad Nacional de \\ Educación a Distancia (UNED), St/Juan del Rosal 12, E28040 Madrid, Spain; erubio@ind.uned.es \\ 2 Department of Design in Engineering, University of Vigo, Campus As Lagoas, 32004 Ourense, Spain; \\ diecapor@gmail.com \\ 3 Department of Surface Chemistry, Leitat Technological Center, C/Innovació 2, E08225 Terrassa, Spain; \\ csantacruz@leitat.org \\ * Correspondence: betbenedicto@gmail.com; Tel.: +34-660-127-618 \\ + Programa de Doctorado en Tecnologías Industriales.
}

Received: 6 October 2020; Accepted: 15 October 2020; Published: 19 October 2020

\begin{abstract}
In cutting operations of titanium alloys, most of the problems are related to the high consumption of cutting tools due to excessive wear. An improvement of metalworking fluid (MWF) technology would increase the productivity, sustainability, and quality of machining processes by lubricating and cooling. In this research article, the authors varied the surfactant's charge, the hydrocarbon chain length, and the ethoxylation degree. Surfactants were dispersed at $1.2 \mathrm{mM}$ in water and trimethylolpropane oleate to produce water-based MWF. Infrared reflection absorption spectroscopy and total organic carbon analysis were used to study the influence of surfactant structure on the film forming ability of the emulsion and performance was studied on Ti6Al4V using tapping torque test. The results showed that by changing the molecular structure of the surfactant, it is possible to vary the affinity between the ester and the substrate and reach an optimal combination, which improves the formation of a tribofilm. The mixture with anionic surfactants has good tribology performance, while non-ionic surfactants shorten the tool's life. Moreover, the increase in the hydrocarbon chain length and the number of ethoxylations of surfactants promotes the adhesion of ester onto the metal surface, improving the lubricity properties of environmentally friendly MWF.
\end{abstract}

Keywords: metalworking fluid; tool wear; tool life; Ti6Al4V; surfactant

\section{Introduction}

Titanium and its alloys are considered difficult-to-cut materials due to their low thermal conductivity, high hardness, and high chemical reactivity at elevated temperatures. Most of the problems related to conventional machining of titanium alloys are associated with the high consumption of cutting tools due to excessive wear caused by the high temperature reached during the cutting process as well as the tendency of the chip to weld to the tool. Unfortunately, the lack of BUE (Built-up edge) also increases abrasion and chip welding. The combination of these characteristics and the relatively poor thermal conductivity of titanium causes unusually high temperatures at the tool's edge [1], causing premature tool failure and promoting corrosion, residual stress formation, and micro-cracks [2].

Wear mechanisms depend on the tool material type. Tungsten carbide (WC) cutting tools are the most suitable tool materials commercially available in almost all machining processes [3] due to their low cost and availability [4]. However, coating on carbide tools has no beneficial effect on their 
performance. Chemical vapor deposition (CVD) coated carbides and ceramic tools are not generally used in titanium machining due to their higher reactivity with titanium and their relatively low fracture toughness as well as the poor thermal conductivity of most ceramics [5].

In general, low machining speeds are used to lengthen the tool life. At increased cutting speeds, high compressive stresses and high temperatures are generated near the cutting edge [6]. Under these conditions, the dominant wear mechanisms are plastic deformation and crack development because of thermal shock. The variation of feed, cutting depth, or cutting speed modifies the degree of wear, but also it is greatly affected by the type of metalworking fluid (MWF) used [7]. Depending on the fluid type, tool life may be prolonged up to 30\% [8]. MWF must be both a coolant and a lubricant to decrease the cutting forces and avoid chip welding. However, most formulations are developed for ferrous metals and aluminum alloys, and few efforts have been made to design an effective MWF for machining titanium alloys [9].

Conventional MWFs are, in general, derived from petroleum, which is heavily toxic and can have negative effects on the environment and especially on human health. New technologies that include dry machining, minimum quantity lubrication (MQL) [10], cryogenic and gaseous cooling, incorporation of nanofluids into polymer matrix [11] or in MWF [12], environmentally friendly lubricants [13], and combinations of them [14] have gained increasing interest within the sector and led to the exploration of even broader opportunities to reduce or to completely eliminate conventional MWFs [15]. As such, new sustainable MWFs from vegetable oil or raw material from renewable sources have been seriously considered [16] in the manufacturing industry as an alternative to petroleum-based oils [17]. Ester-based fluids have gained interest from both the research community and industrial users [18] because of their excellent lubricity over a wide temperature range in the boundary lubrication zone [19]. In addition, synthetic esters provide corrosion protection and, in contrast to neat vegetable oils, they have high oxidative stability [20].

The number of variables required to formulate a water-based MWF (e.g., workpiece material, cutting operation, and cutting parameters) is too large to describe all possible formulations. MWFs are most often sold as concentrates that are diluted between 3 and $20 \%$ in water. This MWF type can be classified according to DIN 51385 [21] concerning their oil content in emulsions and solutions. Due to its growing demand, the present work is focused on the study of emulsions, particularly oil in water $(\mathrm{O} / \mathrm{W})$ emulsions, which are widely used in cutting processes. The oil (dispersed phase) functions as a lubricant, reducing friction between the contact surfaces, while the water (continuous phase) helps to evacuate the heat generated, thanks to its greater heat capacity [22]. For the emulsion to help improve lubrication, the oil must reach the substrate and replace water. The oil droplet is attracted to the metal surface by Van der Waals forces, while the electrostatic interaction between the oil and the negatively charged surfaces is repulsive [23].

Surfactants are used to stabilize the oil drops in the water phase by their amphiphilic molecular structure [24]. Their adsorption at the solid-liquid interface is strongly dependent on [25] the nature of the solid substrate and the molecular structure of the surfactant and the aqueous phase properties-for example, $\mathrm{pH}$, electrolyte content, and temperature. Surfactants modify surface properties, influencing the lubrication performance [26]. They can be classified according to their dissociation power in the presence of an electrolyte as ionic or non-ionic. Within the ions as a function of charge, they are classified as anionic, cationic, and amphoteric [27]. Cationic surfactants, such as quaternary ammonium salts, have anti-corrosive and bactericidal properties and can significantly improve water lubricity [28] by reducing surface tension and forming a durable lubricating film [29]. However, they are not typically used in MWF formulations as they are more expensive and non-compatible with anionic [30]. Non-ionic surfactants do not bear an electrical charge and therefore have the advantage that they do not interact with calcium and magnesium ions in the water used for dilution. Surface activity depends primarily on the hydrophilic and hydrophobic part [31]. Even though anionic surfactants are, in general, much more sensitive to water hardness, they improve the wettability of the cutting fluid on 
the metal surface due to the adsorption of surfactant monomers onto the surface [32] and they are considerably less expensive than non-ionic surfactants [33].

Previous work has shown that there are many phenomena involved in lubrication with $\mathrm{O} / \mathrm{W}$ emulsions. It is a complex system in which the physicochemical interactions between oil, water, and the surface control the lubrication mechanisms [34]. Recently, new studies have been published confirming that more knowledge of the MWF composition is needed [35], that emulsion lubrication is still not fully understood [36], and that there is still no agreement on the influence of various parameters such as stability or droplet size of emulsions on tribological behavior [37].

The aim of this study is to provide valuable information relating to the formulation of a sustainable and effective MWF by assessing the lubricity performance on Ti6Al4V. It aims to formulate a new MWF formulation including a renewable ester as the base oil and a mixture of two surfactants. Previous studies have demonstrated that mixed surfactants are synergistic [24]; they have a greater solubilization capacity and higher emulsion stability by increasing the packing density of the surfactant around the oil droplet. Although mixtures of anionic and non-ionic surfactants are commonly used in the metallurgical industry, they are not well known at the molecular level [38]. Surfactants with different charge, hydrocarbon chain length, and ethoxylation degree were used to identify the optimum surfactant that promotes the adhesion of the ester onto the Ti6Al4V surface. Moreover, this study reports the performance of the MWF by tapping torque tests against the surfactants used in the emulsion.

\section{Materials and Methods}

To develop a sustainable and effective MWF that provides improved Ti6Al4V machining, the surfactant molecular structure was modified to study its interaction with the ester oil when building up a lubricant film on the titanium surface. Using water-based lubricant improves heat removal due to its very high thermal conductivity. However, it is also necessary to use other substances to reduce the friction coefficient, such as a biodegradable and renewable fatty acid ester.

This work aims to point out the benefits of using sustainable water-based lubricants as an alternative to mineral oil and to report the preliminary experimental investigations for a future comparison with other lubrication and cooling systems. The procedure includes two main phases: the ability of the MWF to form a tribofilm and the lubricity performance (Figure 1). Several emulsions were prepared (Section 2.1). With these MWFs, a surface analysis was conducted according to the method presented by Benedicto et al. [39] to quantify the amount of organic matter, specifically trimethylolpropane trioleate (TMP oleate) (Section 2.2). The film forming ability of the emulsion considering surfactant structure is then related to the lubricity performance by tapping torque test (Section 2.3).

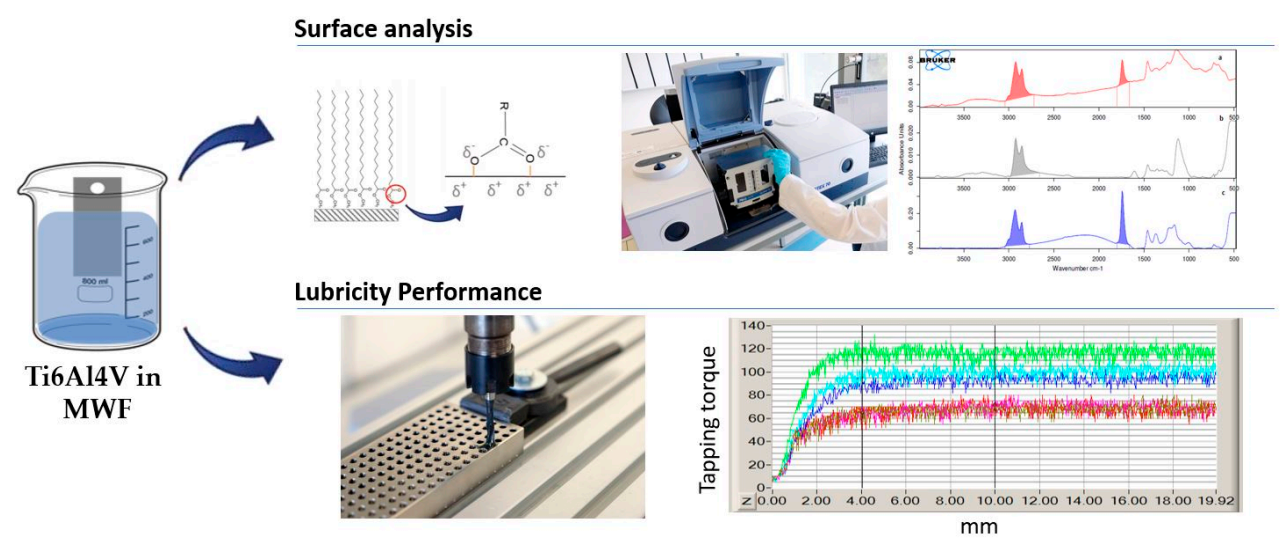

Figure 1. Test set-up diagram to study the role of surfactant structure on the ability to build up a lubricating film. 


\subsection{Materials and Mix Proportions: Preparation of Emulsion}

Numerous specialty additives can be found in MWF formulations, such as anti-corrosive agents, foam stabilizers, bactericides, and fungicides. The products formulated in this work are simplified systems compared to commercial concentrates. Nevertheless, they contain the main raw materials: oil, water, $\mathrm{pH}$ buffer, and surfactants. The concentrations of the ingredients were selected based on the common MWF formulation used in Zhao et al.'s [40] previous study (Table 2):

- The oil phase: this is a fatty acid ester trimethylolpropane trioleate or TMP oleate, Weichol 3/134W from Industrial Química Lasem (IQL, Castellgalí, Spain), commercially used as environmentally adapted lubricant [41].

- The aqueous phase: this is a solution of 2-aminoethanol (MEA) (supplied by Across, Noisy Le Grans, France) in distilled deionized water to reach and maintain a $\mathrm{pH}$ above 9. The ideal $\mathrm{pH}$ of water-based MWF is within the range 8.5 to 9.5. At this condition, it prevents corrosion on ferrous metals, minimizes the potential for contact dermatitis, and controls biological growth [42,43].

- The surfactant blend: this is a mixture of a non-ionic surfactant oleyl/cetyl propoxylated alcohol with the trade name Dehypon OCP502 (BASF, Ludwigshafen, Germany) and the different surfactants under study (Kao Chemicals GmbH, Emmerich, Germany) (Table 1) with a 2:3 ratio. Adding a non-ionic surfactant allows closer packing at the interface and it contributes to stabilizing the emulsion. The oleyl/cetyl propoxylated alcohol was selected according to guidelines for formulating microemulsions from the experimental results of the study conducted by Zhao et al. [40], where the hydrocarbon chain length of the non-ionic surfactant should be equal to or greater than the hydrocarbon chain length of the oil fatty acids.

Table 1. Properties of surfactants under study from Kao Chemicals GmbH.

\begin{tabular}{ccccc}
\hline Charge & Abbreviation & Chain & Ethoxylation Degree (EO) & Chemical Name \\
\hline \multirow{5}{*}{ Anionic } & AC8E8 & C8 & $8 \mathrm{EO}$ & Capryleth-9 carboxylic acid \\
& AC12E4.5 & C12 & $4.5 \mathrm{EO}$ & Laureth-6 carboxylic acid \\
& AC12E10 & C12 & $10 \mathrm{EO}$ & Laureth-11 carboxylic acid \\
& AC18E2 & C18 & $2 \mathrm{EO}$ & Oleth-3 carboxylic acid \\
& AC18E5 & C18 & $5 \mathrm{EO}$ & Oleth-6 carboxylic acid \\
& AC18E9 & C18 & $9 \mathrm{EO}$ & Oleth-10 carboxylic acid \\
\hline \multirow{5}{*}{ Non-ionic } & NC8E8 & C8 & $8 \mathrm{EO}$ & Octyl alcohol, ethoxylated \\
& NC12E4.5 & C12 & $4.5 \mathrm{EO}$ & Lauryl alcohol, ethoxylated \\
& NC12E10 & C12 & $10 \mathrm{EO}$ & Lauryl alcohol, ethoxylated \\
& NC18E5 & C18 & $2 \mathrm{EO}$ & Oleyl alcohol, ethoxylated \\
& NC18E10 & C18 & $5 \mathrm{EO}$ & Oleyl alcohol, ethoxylated \\
& & & $9 \mathrm{EO}$ & Oleyl alcohol, ethoxylated \\
\hline
\end{tabular}

Table 2. Chemical composition of emulsions, in molar concentration.

\begin{tabular}{cc}
\hline Product & Molar \\
\hline TMP Oleate & 0.0010 \\
Dehypon OCP 502 & 0.0008 \\
Surfactant under study & 0.0012 \\
\hline
\end{tabular}

From a fundamental research point of view, pure substances should be used as surfactants. Considering the final use of the results obtained, the authors tried to ensure that the lubricating substance had adequate performance characteristics and was commercially available. Therefore, the surfactants under investigation have some polydispersity in the ethoxylation degree (EO) and the hydrocarbon chain distribution. 


\subsection{Determination of Fatty Acid Ester Content on Ti6Al4V Surface}

In these experiments, it is important to know the composition at the metal surface, as it could differ from the composition in the bulk, i.e., the original composition of the emulsion. The ester adhered on the Ti6Al4V surface was quantified according to Benedicto et al. [39] by the use of infrared reflection absorption spectroscopy (IRRAS) with Vertex 70 (Bruker, Ettlingen, Germany) and total organic carbon (TOC) quantification with Leco RC612 (Leco, St Joseph, MI, US).

Following the method, calibration curves were built for each surfactant, varying the concentration of TMP oleate in the surfactant blend and using a Fourier transform infrared spectrophotometer Iraffinity-1S (Shimadzu, Nagoya, Japan). The ratio between the integrated absorbance under $\mathrm{C}=\mathrm{O}$ peak and under $\mathrm{CH}_{2}$ stretching vibration peaks (REO) was calculated for each mixture using OPUS software. The equation from each regression line allowed us to determine the percentage of ester $(w / w)$ given a REO value from a spectrum (Figure 2).
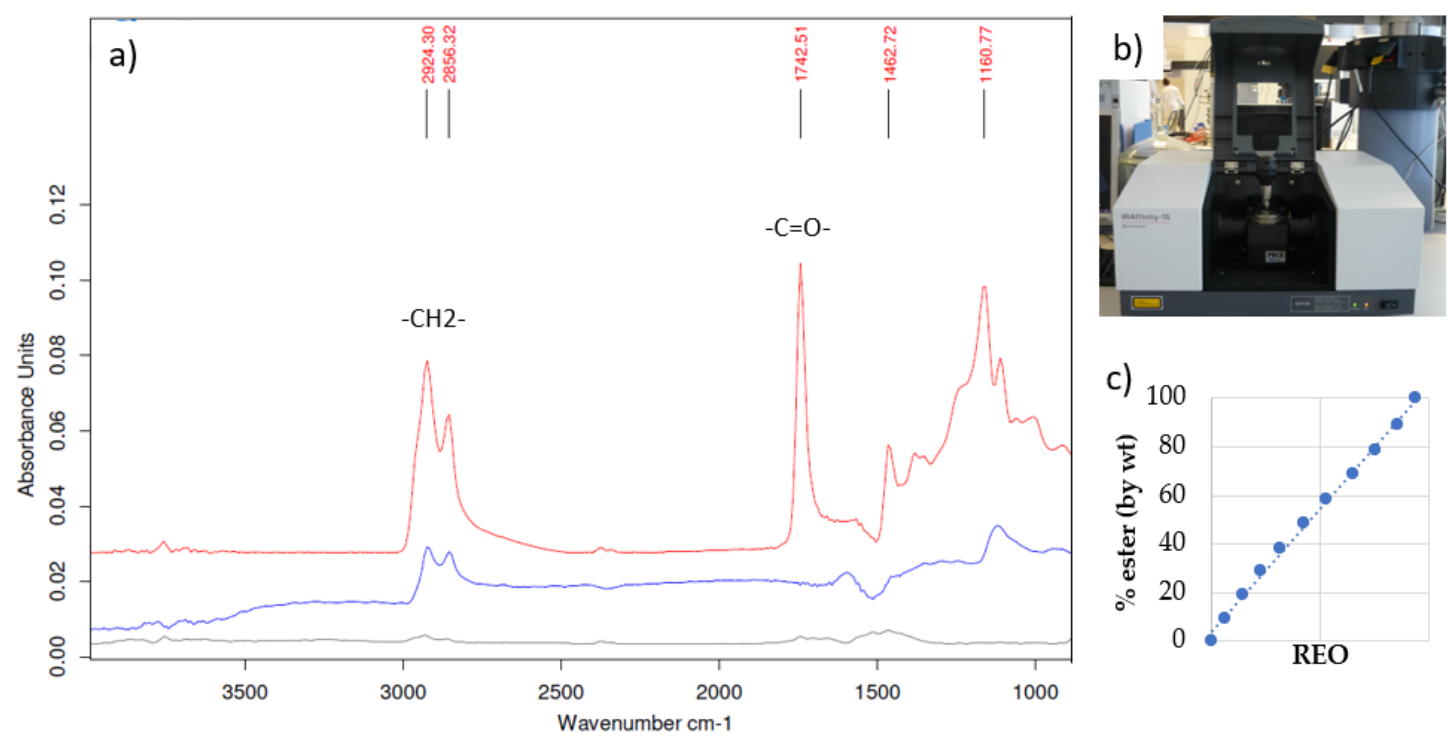

Figure 2. Determination of fatty acid ester on metal surface: (a) spectrum of an emulsion with the $\mathrm{C}=\mathrm{O}$ characteristic peak of an esters; (b) Iraffinity-1S (Shimadzu, Nagoya, Japan); (c) calibration curve.

Ti6Al4V strips are pretreated with hexane to clean the surface and, after, they are dipped in the MWF formulation for $10 \mathrm{~min}$ at room temperature. On the one hand, TOC was measured to quantify the amount of organic matter on the strip surface, calculated according to the molecular weight and the number of carbon atoms. On the other hand, strips were evaluated with IRRAS and spectra were analyzed to calculate the REO and determine the percentage of ester adhered on the metal through the calibration curves. From both analytical techniques, the amount of ester and the total organic matter of the lubrication layer were determined.

\subsection{Tapping Torque Test for Tribological Study}

The tapping torque test was used to determine the role of the surfactant's molecular structure in MWFs as it is very sensitive to lubrication condition $[44,45]$. Formulations were evaluated based on the standard ASTM D5619 for comparing metal removal fluids [46]. Tribological test was conducted using the taping torque test Labtap G8 (Microtap, Munich, Germany) (Figure 3) and Ti6Al4V workpiece material. Cutting parameters were mostly determined by the material that was being machined. Spindle speed and depth of cut were selected at $300 \mathrm{rpm}$ and $6 \mathrm{~mm}$, respectively, as presented in Table 3.

In the tapping process, taps were filled with the test formulation. A rotating torque (cutting torque) was produced, and the performance was reported as tapping torque $(\mathrm{N} \cdot \mathrm{cm})$ mean value, as an average of the generated work performance. Tapping torque lower values indicate better MWF performance. 
In Figure 4, during the tapping process, a graphical measurement of the torque is shown: beginning of cut to full contact of all chamfer teeth (tap entrance) and cutting torque of the tap that is now cutting with all its chamfer teeth [47]. Due to due to the high tool wear when machining titanium alloys, a new tool was used for each product under study. As the tool wear rate progresses in each tapping process, the microtap mean value increases. The taps were made until the tool broke or reached a maximum of 15 cuttings.

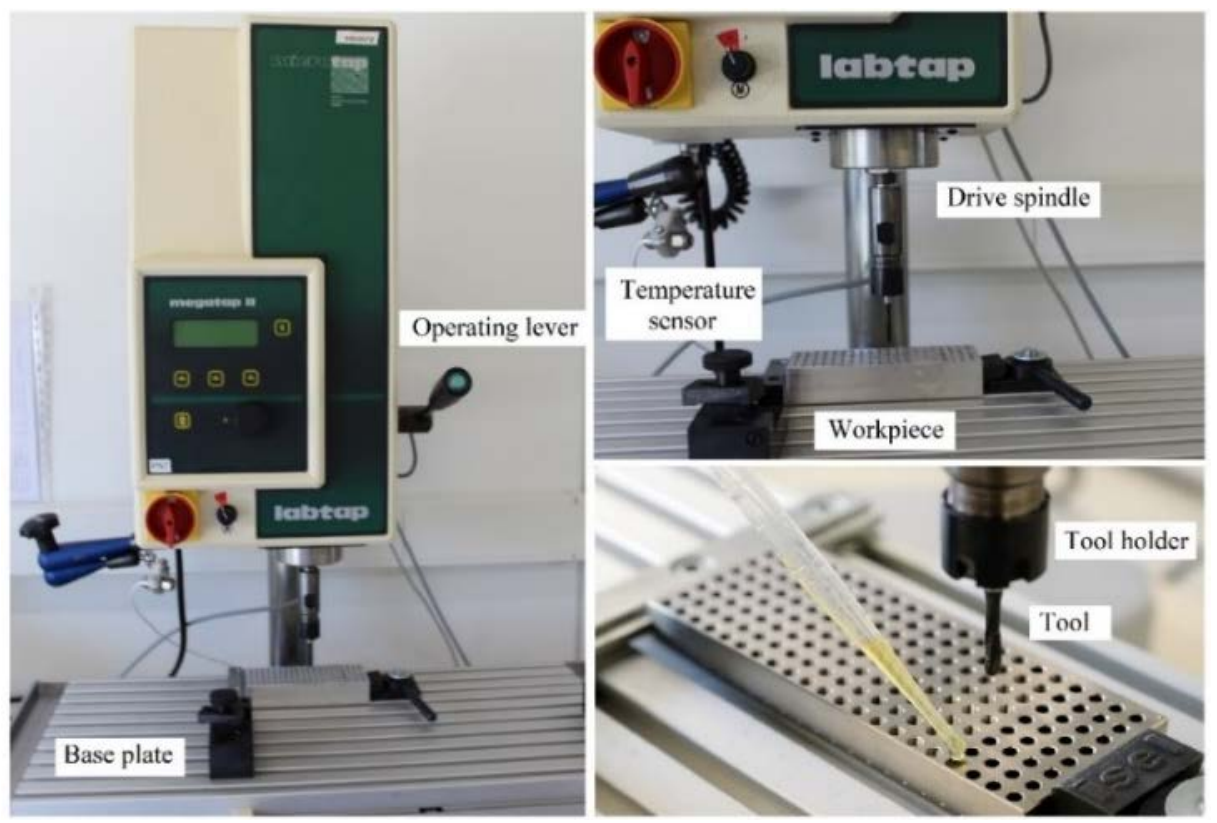

Figure 3. Experimental setup: tribological test using a tapping torque test system with Ti6Al4V workpiece.

Table 3. Machining conditions.

\begin{tabular}{cc}
\hline Parameter & Value \\
\hline Spindle speed $(\mathrm{rpm})$ & 300 \\
Depth of cut $(\mathrm{mm})$ & 6 \\
Hole diameter $(\mathrm{mm})$ & 3.3 \\
Tapping tool & TTT_M4C \\
Workpiece material & Ti6Al4V pre-drilled \\
\hline
\end{tabular}

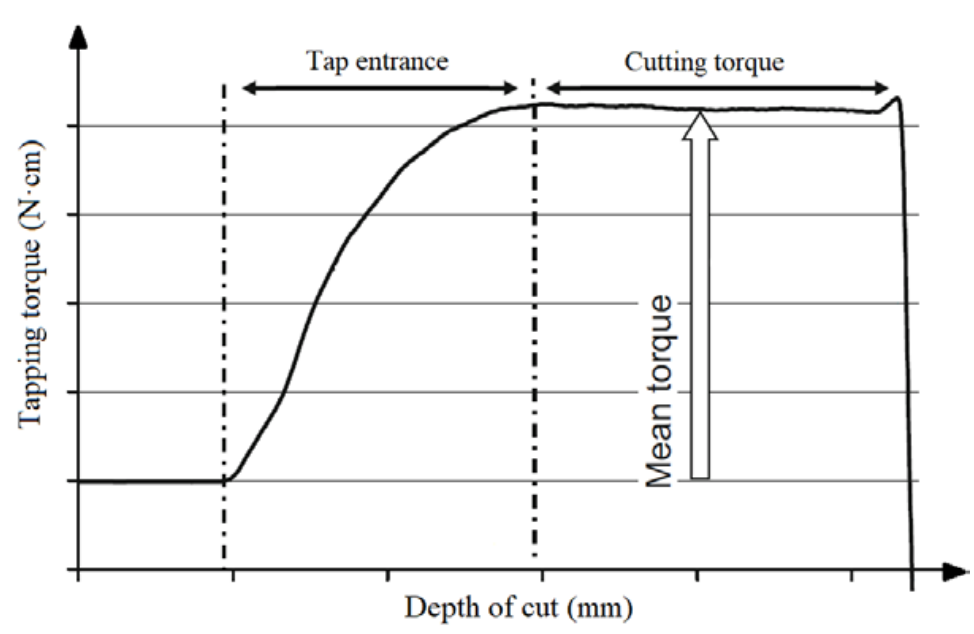

Figure 4. Measurement of the tapping torque during cutting. 


\section{Results and Discussion}

\subsection{Effect of Surfactant Charge on the Lubricity Performance of Emulsions}

To study the impact of anionic and non-ionic surfactant molecular structure on the lubricity performance of MWF products, a surfactant system was generated for each substance listed in Table 1. An amine balance was added to maintain the $\mathrm{pH}$ at 9.2. Moreover, the total molar concentration of fatty acid ester and surfactant was kept constant.

For comparison between surfactant charges, equivalent anionic and non-ionic surfactants with different hydrocarbon chain lengths and ethoxylation numbers were tested. Results are plotted in Figure 5, where the bars represent the amount of ester adhered on the Ti6Al4V strips (in $\mu$ mol) after being treated with the several MWF emulsions containing the surfactant under study and points show the tapping torque mean value (TTT) from each formulation.

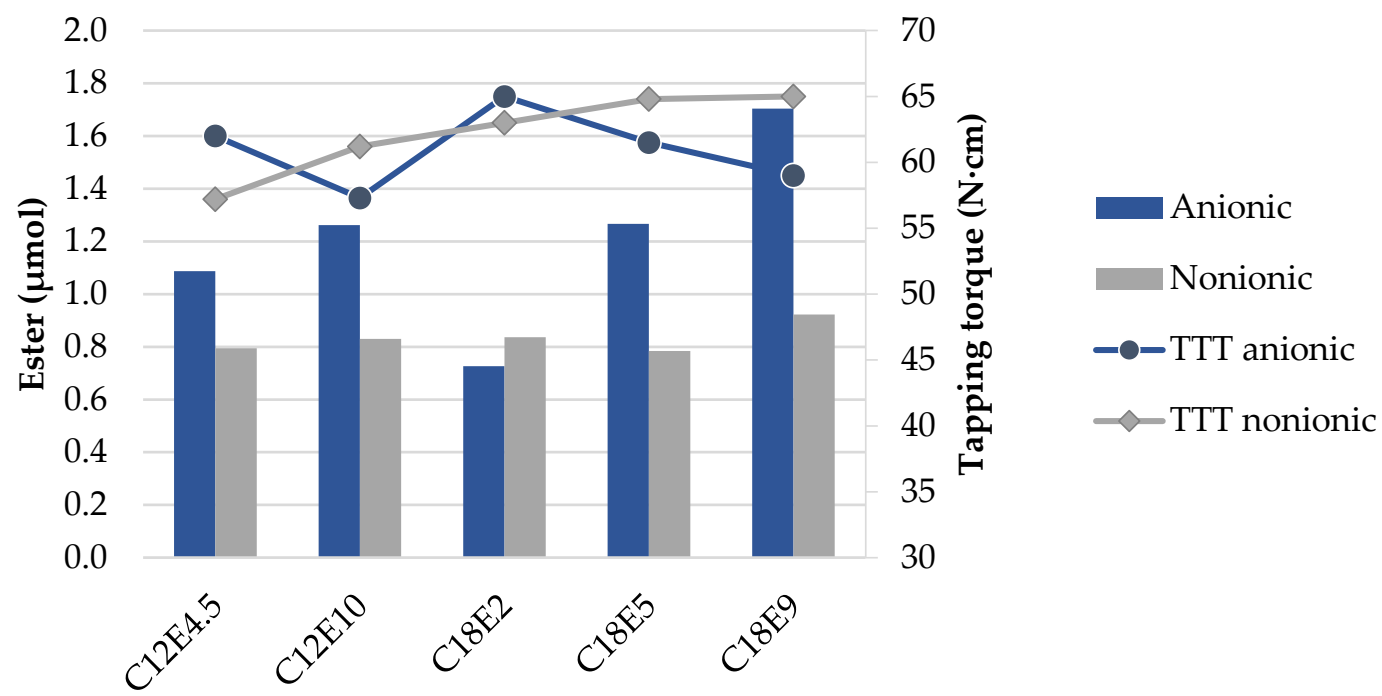

Figure 5. Amount of fatty acid ester adhered on titanium alloy strips after treatment with several emulsions. Points correspond to the first tapping torque value (TTT) for each emulsion.

Results show that all the MWFs formulated with the non-ionic surfactants have similar amounts of ester adhered on the metal surface, meaning that their structures have little impact on the adherence of TMP oleate regardless of the hydrocarbon chain length and ethoxylation degree. Compared to non-ionic surfactants, anionic surfactants promote the adhesion of ester on the Ti6Al4V strips. Data also indicate that the molecular structure of anionic surfactants has an influence on the amount of ester on the titanium alloy surface. Moreover, the ester adhered on the strip is plotted against the lubricity performance (TTT). For MWFs containing anionic surfactants, the more ester is adhered to the metal surface, lower the tapping torque values are.

To further explore the lubricity performance for each emulsion, tapping was run until 15 taps were achieved or until the tool broke, meaning that the tool and the workpiece were welded (Figure 6). After each tap, there was an increase in the tapping torque, due to tool wear. This increment depends on the anti-wear properties of the MWF and its ability to form a tribofilm. 

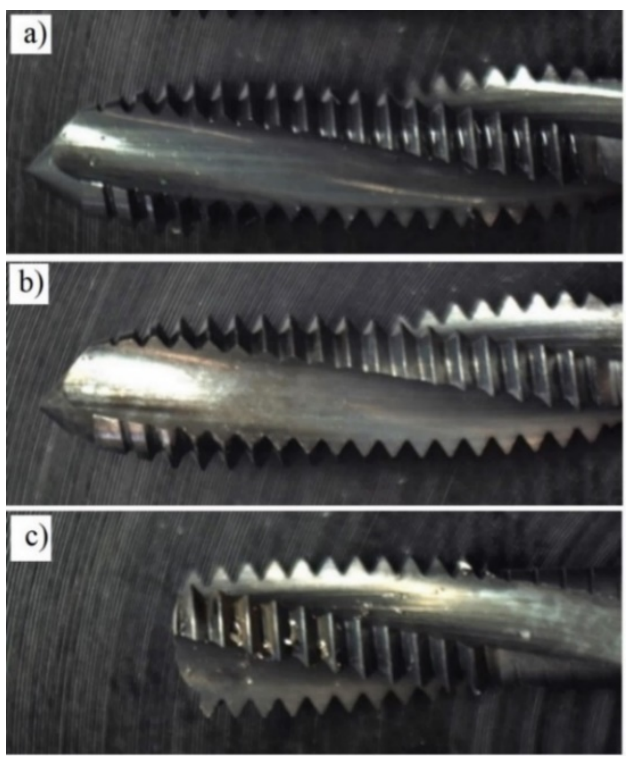

Figure 6. Tool life: (a) new cutting tool; (b) cutting tool after 15 cuts with an anionic surfactant emulsion;

(c) broken tool after tapping with a non-ionic surfactant emulsion.

It was observed that the tools used with the combination of non-ionic surfactants welded at the tenth cut and, for one surfactant (NC18E5), before reaching the seventh cut. However, anionic surfactants have greater anti-wear properties, prolonging the tool life (Figure 7). None of the tools used with the negatively charged surfactants were broken during the study. This behavior could be explained by the fact that the anionic surfactant tends to promote the ester adsorption onto sliding surfaces, thus forming a lubricating film that prevents direct metal contact. Consequently, the increase in the tapping torque values with each consecutive cut is lower compared to non-ionic surfactant.

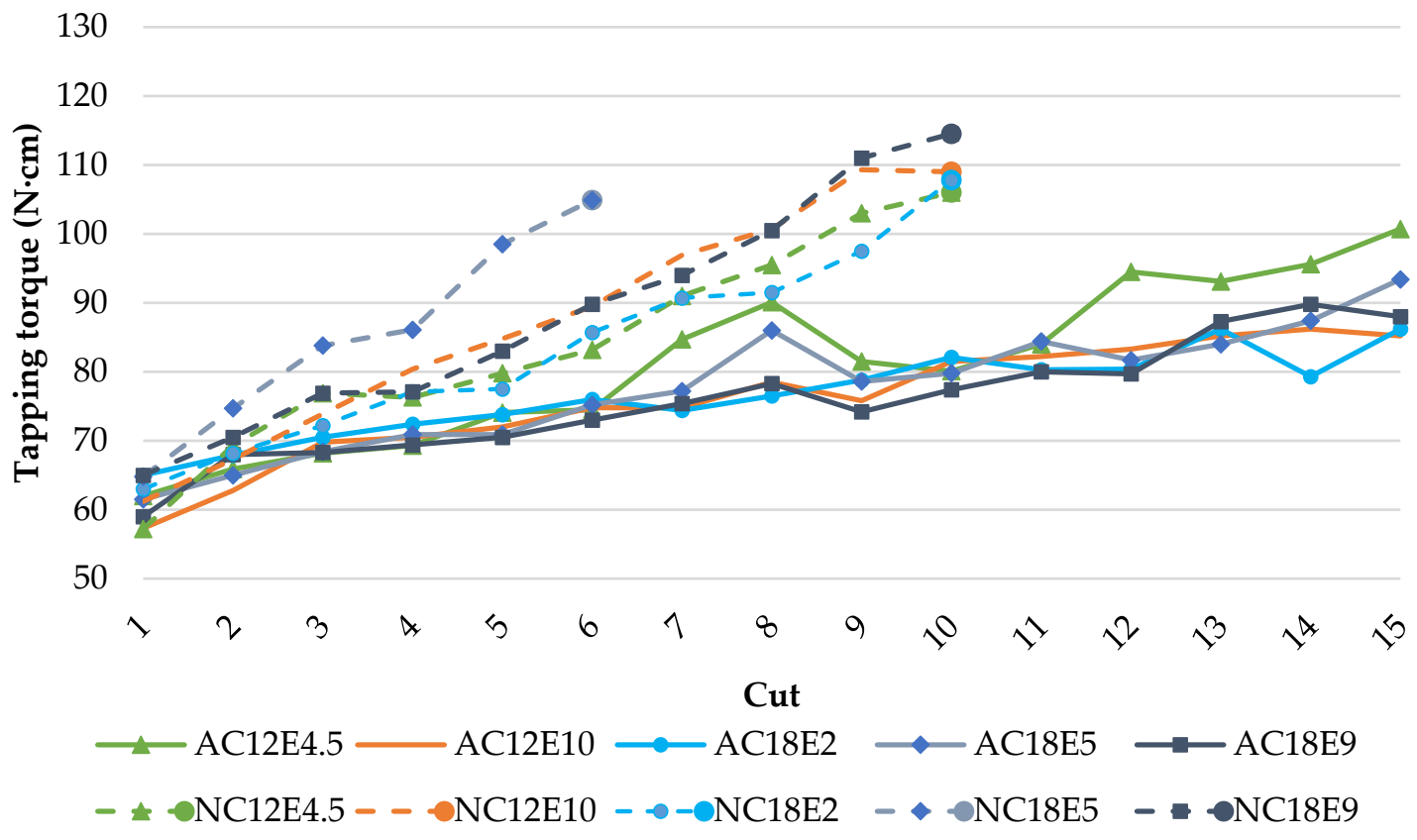

Figure 7. Evolution of the tapping torque with machining of consecutive cuttings: anionic with continuous line and non-ionic with dashed line. 


\subsection{Effect of Surfactant's Hydrocarbon Chain Length on the Tribological Performance of Emulsions}

In order to study the influence of surfactant's hydrocarbon chain length on the emulsion system, tests were performed for surfactants with similar numbers of ethoxylations and varying the number of carbons of the lipophilic part from 8 to 18. The analysis of the Ti6Al4V surface, treated with the different emulsions, is presented in Figure 8. Bars represent the total organic matter adhered onto the titanium alloy surface. The upper part indicates the amount of ester (also noted with a number), while the lower part shows the other organic compounds such as amine and the surfactant mixture. Moreover, the tapping torque mean value (TTT) for each formulation is represented as points. The distance between different markers denotes the tool wear after the first and fifth cut with the MWF; lower distance means less tool wear.

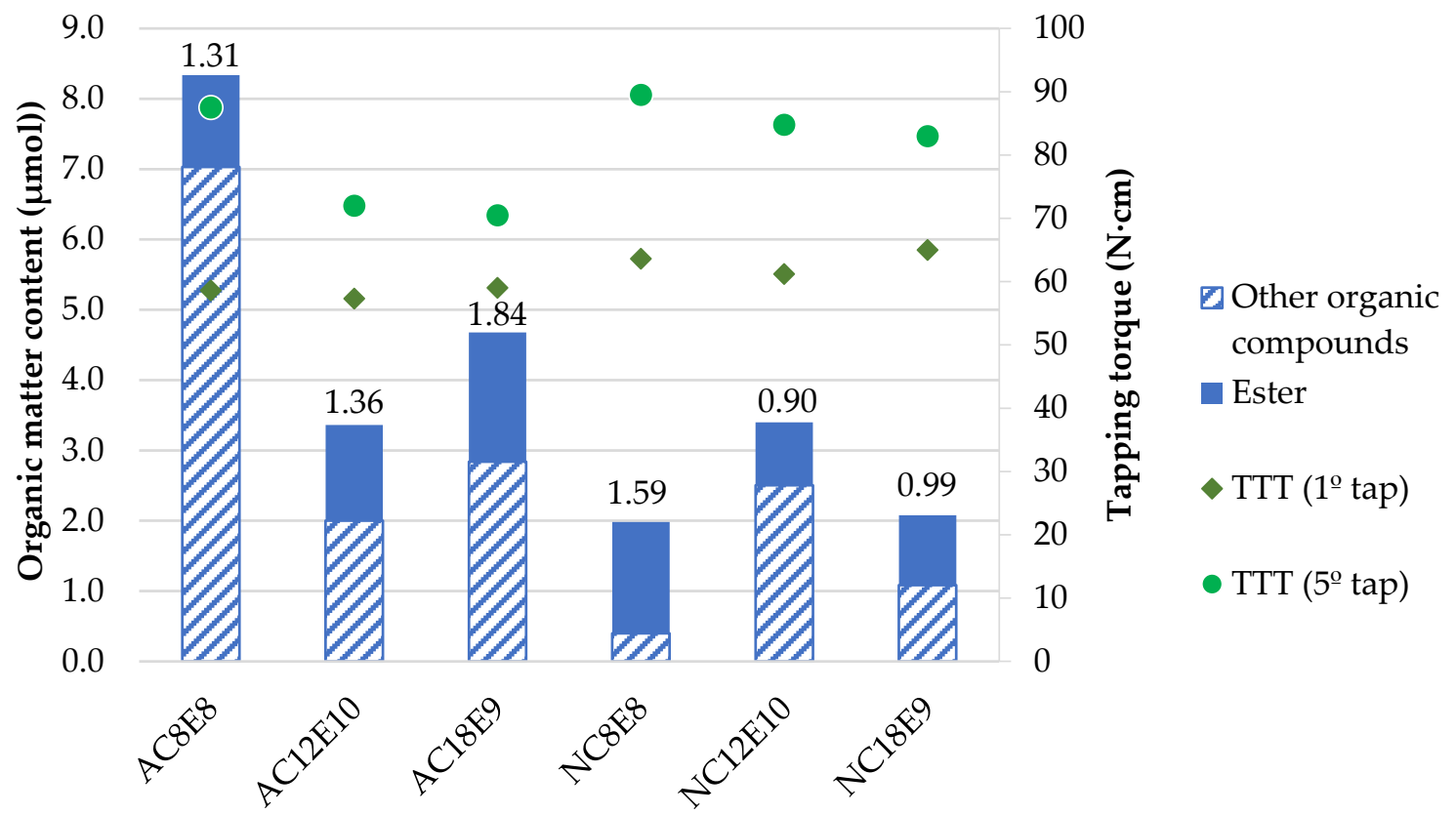

Figure 8. Evolution of the tapping torque with machining of consecutive cuttings: anionic with continuous line and non-ionic with dashed line.

Results pointed out that the concentration of ester increases with the length of the hydrocarbon chain of the anionic surfactant, making it more lipophilic. As other researchers have also demonstrated [48], the MWF with more lipophilic surfactant is found to form a stronger tribofilm, reducing the tapping torque values. Shorter hydrocarbon chain length has greater distance between the first and the fifth tap values, meaning higher tool wear. Similar trend in the anti-wear performance is observed when increasing the lipophobicity of non-ionic surfactants. However, the amount of organic matter is lower than the anionic surfactant and, thus, the highest TTT values are achieved.

The high amount of organic matter in the AC8E8 emulsion can be explained by its instability. Surfactants with a hydrocarbon chain of eight carbons are very unstable, as the study by Zhao et al. [40] predicted. This suggests that the difference between the chain lengths of the mixed surfactants should be less than six to maximize the range of stable emulsions.

The difference between the first and the fifth tapping torque mean value $(\Delta)$ was adopted as the measure of tool wear. The results presented in Figure 9 show that as the surfactant's hydrocarbon length chain increases (more lipophilic) as it forms a more robust tribofilm that allows for decreasing the wear, regardless of whether it is anionic or non-ionic. 


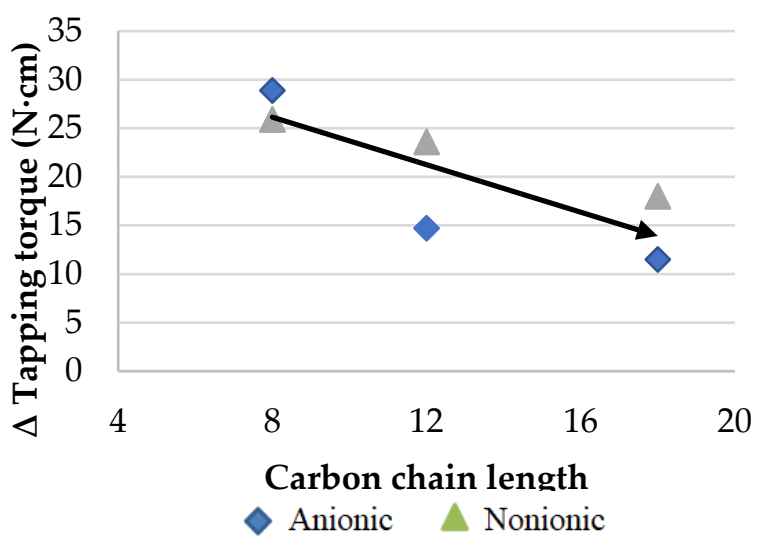

Figure 9. Difference in tapping torque between the first and fifth cut versus carbon chain length.

\subsection{Effect of Anionic Surfactant's Ethoxylation Degree on the Tribological Performance of Emulsions}

The influence of the number of ethoxylations (EO) in the surfactant has been studied with surfactants of 12 and 18 carbons in their lipophilic chain. Although the charge and hydrocarbon chain length of the surfactant have significant effects, the number of ethoxylations also plays an important role. On the one hand, with increasing ethoxylation degree within the same hydrocarbon chain length, a smaller amount of organic matter is adhered on the surface. MWF is more soluble due to the number of EO groups increasing the hydrophilic/lipophilic balance (HLB).

On the other hand, Figure 10 shows that even though there is less surfactant on the surface, the amount of ester increases, forming a more resistant layer and therefore improving the lubricity performance. This is in line with another study that revealed that higher ethoxy group content was found to improve anti-wear properties [49]. As a result, a surfactant with a higher number of ethoxylate groups is preferred.

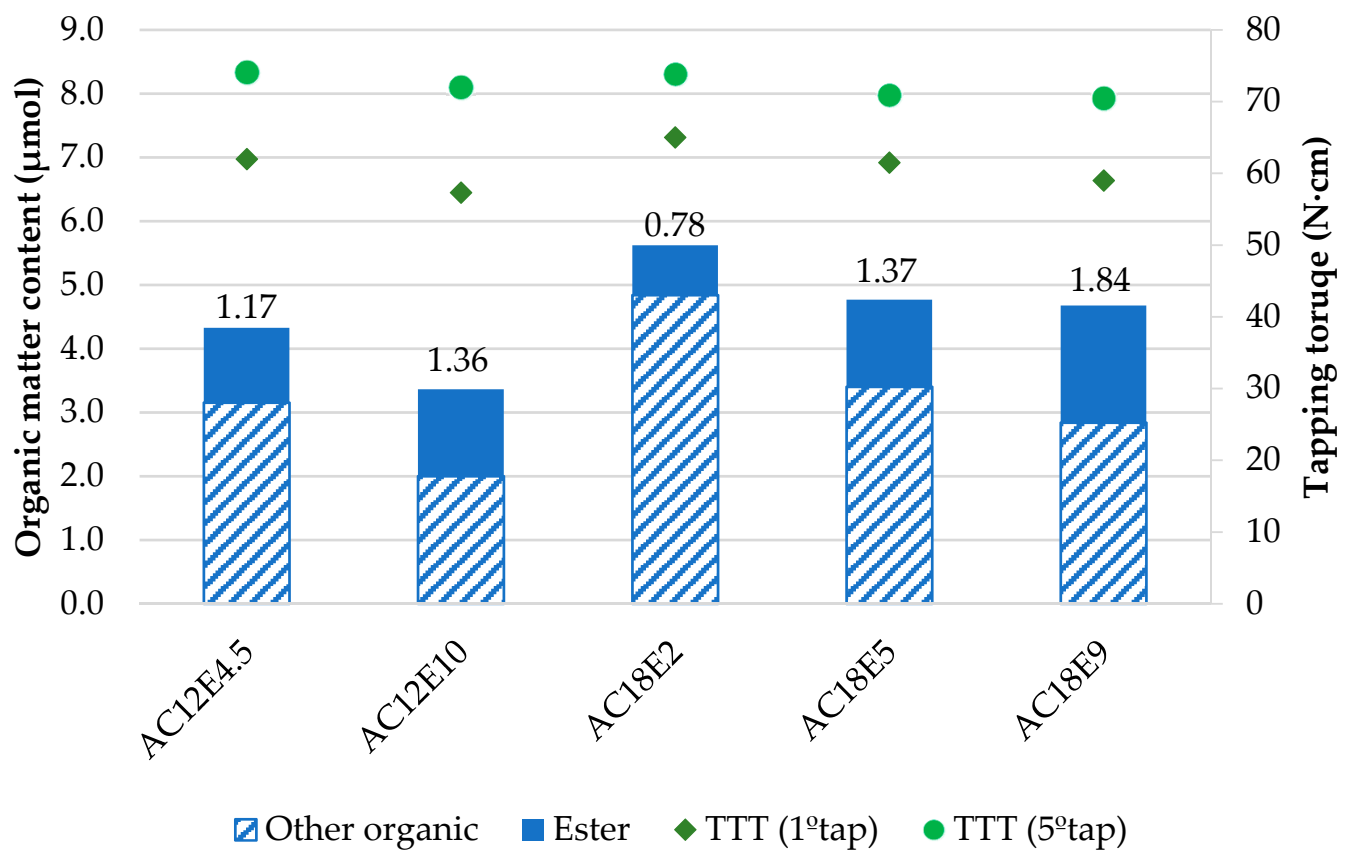

Figure 10. Organic matter adhered on Ti4Al4V strips treated with formulations containing different anionic surfactants with different ethoxylations against its lubricity performance. 


\section{Conclusions}

The surfactant used to disperse the oil in water and stabilize the emulsion controlled the ester adhered onto the metal substrate. By changing the molecular structure of the surfactant, it is then possible to vary the affinity between the ester and the substrate and to reach an optimal combination, which enables easy adherence onto the contact zone and improves the formation of a tribofilm. In this paper, the authors varied the surfactant's charge (anionic and non-ionic), the hydrocarbon chain length, and the ethoxylation degree. The surfactants were dispersed at $1.2 \mathrm{mM}$ molar concentration in water to study the emulsion behavior with the Ti6Al4V surface. Moreover, tribological experiments with tapping torque machine were conducted in $\mathrm{O} / \mathrm{W}$ emulsion. The main conclusions drawn from this study are listed below:

- It was found that, from the surfactants tested, non-ionic surfactants are less promising and their structures have little impact on the adherence of TMP oleate. The application of surfactants bearing an anionic group can be successful, as they not only promote TMP oleate adhesion, but also, they improve the anti-wear.

- The data also indicate that the molecular structure of anionic surfactants has a high impact on the amount of ester adhered on the titanium alloy surface, forming a lubricating film that prevents direct metal contact. The more ester is adhered, the lower the tapping torque values are, indicating less wear.

- The concentration of ester increases with the hydrocarbon chain length of the anionic surfactant, as it becomes more lipophilic. However, surfactants with a hydrocarbon chain below eight carbons show high emulsion instability.

- It was apparent that the longer the hydrocarbon chain of the surfactant is, the higher the wear reduction is, regardless of surfactant type, whether it is anionic or non-ionic.

- In the tested anionic surfactants, the higher the number of ethoxylations, the more significant the increase in lubricity observed. Even though there is less surfactant on the surface, due to higher solubility increases, the amount of ester increases, forming a more resistant layer.

The obtained results showed the suitability of a water-based MWF of fatty acid ester for titanium alloy machining. The interactions among the surfactant molecules, the ester, and metal surface play a key role in the lubricity and tool wear protection. Using an anionic surfactant with oleic hydrocarbon chain and a high number of ethoxy groups, such as AC18E9, can lead to better lubricity and tool protection as well as to environmental advantages of ester-based cutting fluids over mineral-based fluids. The research group has also been exploring other fatty acid esters to be used in machining processes with titanium alloys, which are typically applied in the aerospace industry. For further technology evaluation analysis, a comparison of a sustainable water-based MWFs with other lubrication and cooling systems for machining titanium and its alloys is needed.

Author Contributions: Conceptualization, E.M.R. and D.C.; Methodology, E.M.R., D.C., E.B and C.S.; validation, E.B. and C.S.; formal analysis, E.M.R., D.C., E.B. and C.S.; investigation, E.B.; resources, E.B. and C.S.; data curation, E.B. and C.S.; writing-original draft preparation, E.B.; writing-review and editing, E.M.R., D.C. and E.B.; supervision, E.M.R.; project administration, E.M.R.; funding acquisition, E.M.R. All authors have read and agreed to the published version of the manuscript.

Funding: This work was supported by the Research Group of the UNED “Industrial Production and Manufacturing Engineering (IPME)", which has been financed in part by the to the Spanish Ministry of Science, Innovation and Universities (Project RTI2018-102215-B-I00), to the Industrial Engineering School-UNED (REF2020-ICF04) and to the Master in Advanced Manufacturing Engineering.

Acknowledgments: This development has been carried out under the guidance and with close collaboration of Laurent Aubouy and Jaume Josa from Leitat Technological Center. Technical support and information related to surfactants were provided by Michael Stapels from KAO Corporation.

Conflicts of Interest: The authors declare no conflict of interest. The funders had no role in the design of the study; in the collection, analyses, or interpretation of data; in the writing of the manuscript, or in the decision to publish the results. 


\section{References}

1. Amit, P.; Isushil, I.; Yogesh, M.; Manik, N. Machining Challenges in Ti-6Al-4V-A Review. Int. J. Innov. Eng. Technol. 2015, 5, 6-23.

2. Pervaiz, S.; Deiab, I.; Rashid, A.; Nicolescu, M. Minimal quantity cooling lubrication in turning of Ti6Al4V: Influence on surface roughness, cutting force and tool wear. J. Eng. Manuf. 2015, 1-17. [CrossRef]

3. Kumar, U.; Senthil, P. A comparative machinability study on titanium alloy Ti-6Al-4V during dry turning by cryogenic treated and untreated condition of uncoated WC inserts. Mater. Today Proc. 2019, 27, 2324-2328. [CrossRef]

4. Ezugwu, E.O.; Wang, Z.M. Titanium alloys and their machinability. J. Mater. Process. Technol. 1997, 68, $262-274$. [CrossRef]

5. Pramanik, A.; Littlefair, G. Machining of Titanium Alloy (Ti-6Al-4V)—Theory to Application. Mach. Sci. Technol. 2015, 19, 1-49. [CrossRef]

6. Elshwain, A.; Redzuan, N.; Yusof, N.M.; Engineering, M. Machinability of Nickel and Titanium Alloys Under of Gas-Based Coolant-Lubricants (Cls)—A Review. Int. J. Res. Eng. Technol. 2013, 2, 690-702. [CrossRef]

7. Revuru, R.S.; Zhang, J.Z.; Posinasetti, N.R.; Kidd, T. Optimization of titanium alloys turning operation in varied cutting fluid conditions with multiple machining performance characteristics. Int. J. Adv. Manuf. Technol. 2017, 1-13. [CrossRef]

8. Namb, M. Influence of Coolant in Machinability of Titanium Alloy (Ti-6Al-4V). J. Surf. Eng. Mater. Adv. Technol. 2011, 1, 9-14. [CrossRef]

9. Yang, Y.; Zhang, C.; Dai, Y.; Luo, J. Tribological properties of titanium alloys under lubrication of SEE oil and aqueous solutions. Tribol. Int. 2017, 109, 40-47. [CrossRef]

10. Pervaiz, S.; Anwar, S.; Qureshi, I.; Ahmed, N. Recent Advances in the Machining of Titanium Alloys using Minimum Quantity Lubrication (MQL) Based Techniques. Int. J. Precis. Eng. Manuf. Green Technol. 2019, 6, 133-145. [CrossRef]

11. Yumashev, A.; Mikhaylov, A. Development of polymer film coatings with high adhesion to steel alloys and high wear resistance. Polym. Compos. 2020, 41, 2875-2880. [CrossRef]

12. Nune, M.M.R.; Chaganti, P.K. Development, characterization, and evaluation of novel eco-friendly metal working fluid. Meas. J. Int. Meas. Confed. 2019, 137, 401-416. [CrossRef]

13. Chan, C.H.; Tang, S.W.; Mohd, N.K.; Lim, W.H.; Yeong, S.K.; Idris, Z. Tribological behavior of biolubricant base stocks and additives. Renew. Sustain. Energy Rev. 2018, 93, 145-157. [CrossRef]

14. Benedicto, E.; Carou, D.; Rubio, E.M. Technical, Economic and Environmental Review of the Lubrication/Cooling Systems Used in Machining Processes. Procedia Eng. 2017, 184, 99-116. [CrossRef]

15. Gajrani, K.K.; Ram, D.; Ravi Sankar, M. Biodegradation and Hard Machining Performance Comparison of Eco-friendly Cutting Fluid and Mineral Oil Using Flood Cooling and Minimum Quantity Cutting Fluid Techniques. J. Clean. Prod. 2017. [CrossRef]

16. Talib, N.; Rahim, E.A. Experimental evaluation of physicochemical properties and tapping torque of hexagonal boron nitride in modified jatropha oils-based as sustainable metalworking fluids. J. Clean. Prod. 2018, 171, 743-755. [CrossRef]

17. Reeves, C.J.; Siddaiah, A.; Menezes, P.L. A Review on the Science and Technology of Natural and Synthetic Biolubricants. J. Bio Tribo Corros. 2017, 3, 11. [CrossRef]

18. Cecilia, J.A.; Plata, D.B.; Maria, R.; Saboya, A.; Murilo, F.; De Luna, T.; Cavalcante, C.L.; Rodríguez-Castellón, E. An Overview of the Biolubricant Production Process: Challenges and Future Perspectives. Processes 2020, 8, 257. [CrossRef]

19. Zhang, S. Green tribology: Fundamentals and future development. Friction 2013, 1, 186-194. [CrossRef]

20. Zulkifli, N.W.M.; Azman, S.S.N.; Kalam, M.A.; Masjuki, H.H.; Yunus, R.; Gulzar, M. Lubricity of bio-based lubricant derived from different chemically modified fatty acid methyl ester. Tribol. Int. 2016, 93, 555-562. [CrossRef]

21. DIN. Schmierstoffe-Bearbeitungsmedien für die Umformung und Zerspanung von Werkstoffen-Begriffe; DIN: Berlin, Germany, 2013.

22. Cambiella, A.; Benito, J.M.; Pazos, C.; Coca, J.; Ratoi, M.; Spikes, H.A. The effect of emulsifier concentration on the lubricating properties of oil-in-water emulsions. Tribol. Lett. 2006, 22, 53-65. [CrossRef] 
23. Kumar, D.; Daniel, J.; Biswas, S.K. Tribology of steel/steel interaction in oil-in-water emulsion; a rationale for lubricity. J. Colloid Interface Sci. 2010, 345, 307-315. [CrossRef] [PubMed]

24. Cambiella, Á.; Benito, J.M.; Pazos, C.; Coca, J. Interfacial properties of oil-in-water emulsions designed to be used as metalworking fluids. Colloids Surf. A Physicochem. Eng. Asp. 2007, 305, 112-119. [CrossRef]

25. Rosen, M.J.; Kunjappu, J.T. Adsorption of Surface-Active Agents at Interfaces: The Electrical Double Layer. In Surfactants and Interfacial Phenomena; John Wiley \& Sons, Inc.: Hoboken, NJ, USA, 2012; pp. 39-122.

26. Paswan, B.K.; Mahto, V. Development of environment-friendly oil-in-water emulsion based drilling fluid for shale gas formation using sunflower oil. J. Pet. Sci. Eng. 2020, 191, 107129. [CrossRef]

27. Pegiadou-Koemtjopoulou, S.; Tsatsaroni, E.; Mylona, M. Pyrimidinium cationic surfactants as emulsifiers for oil-in-water emulsions. J. Surfactants Deterg. 1998, 1, 499-502. [CrossRef]

28. Sulek, M.; Wasilewski, T.; Zieba, M. Tribological and physical-chemical properties of aqueous solutions of cationic surfactants. Ind. Lubr. Tribol. 2010, 62, 279-284. [CrossRef]

29. Ji, H.; Zhang, X.; Tan, T. Preparation of a Water-Based Lubricant from Lignocellulosic Biomass and Its Tribological Properties. Ind. Eng. Chem. Res. 2017, 56, 7858-7864. [CrossRef]

30. Zimmerman, J.B.; Clarens, A.F.; Hayes, K.F.; Skerlos, S.J. Design of Hard Water Stable Emulsifier Systems for Petroleum- and Bio-based Semi-synthetic Metalworking Fluids. Environ. Sci. Technol. 2003, 37, 5278-5288. [CrossRef]

31. Sułek, M.W.; Ogorzałek, M.; Wasilewski, T.; Klimaszewska, E. Alkyl polyglucosides as components of water based lubricants. J. Surfactants Deterg. 2013, 16, 369-375. [CrossRef]

32. Benito, J.M.; Cambiella, A.; Lobo, A.; Gutiérrez, G.; Coca, J.; Pazos, C. Formulation, characterization and treatment of metalworking oil-in-water emulsions. Clean Technol. Environ. Policy 2010, 12, 31-41. [CrossRef]

33. Ahmed, N.; Nassar, A.; Zaki, N.; Gharieb, H. Stability and Rheology of Heavy Crude Oil-in-Water Emulsion Stabilized By an Anionic-Nonionic Surfactant Mixture. Pet. Sci. Technol. 1999, 17, 553-576. [CrossRef]

34. Srikant, R.R.; Ramana, V.S.N.V. Performance evaluation of vegetable emulsifier based green cutting fluid in turning of American Iron and Steel Institute (AISI) 1040 steel-An initiative towards sustainable manufacturing. J. Clean. Prod. 2015, 108, 104-109. [CrossRef]

35. Sharma, D.; Pandey, K.M. Ecological friendly functional fluids and lubricant techniques in machining processes: A review. Int. J. Hydromechatronics 2018, 1, 182. [CrossRef]

36. Brinksmeier, E.; Meyer, D.; Huesmann-Cordes, A.; Herrmann, C. Metalworking fluids-Mechanisms and performance. CIRP Ann. Manuf. Technol. 2015, 64, 605-628. [CrossRef]

37. Joyner, H.S.; Pernell, C.W.; Daubert, C.R. Impact of oil-in-water emulsion composition and preparation method on emulsion physical properties and friction behaviors. Tribol. Lett. 2014, 56, 143-160. [CrossRef]

38. Shiloach, A.; Blankschtein, D. Predicting Micellar Solution Properties of Binary Surfactant Mixtures. Langmuir 1998, 14, 1618-1636. [CrossRef]

39. Benedicto, E.; Carou, D.; Rubio, E.M.; Batlle, L. A novel method for the determination of fatty acid esters in aqueous emulsion on Ti6Al4V surface with IRRAS and carbon quantification. Tribol. Int. 2018, 128, 155-160. [CrossRef]

40. Zhao, F.; Clarens, A.; Murphree, A.; Hayes, K.; Skerlos, S.J. Structural aspects of surfactant selection for the design of vegetable oil semi-synthetic metalworking fluids. Environ. Sci. Technol. 2006, 40, 7930-7937. [CrossRef]

41. Rahim, E.A.; Sani, A.S.A.; Talib, N. Tribological Interaction of Bio-Based Metalworking Fluids in Machining Process. Lubr. Tribol. Lubr. Addit. 2018. [CrossRef]

42. Al-Sabagh, A.M. Investigation of oil and emulsion stability of locally prepared metalworking fluids. Ind. Lubr. Tribol. 2012, 64, 346-358. [CrossRef]

43. Rao, D.N.; Srikant, R.R.; Rao, C.S. Influence of emulsifier content on properties and durability of cutting fluids. J. Braz. Soc. Mech. Sci. Eng. 2007, 29, 396-400. [CrossRef]

44. Pereira, I.C.; Da Silva, M.B.; Da Cunha, D.F.; Sales, W.F. Analysis of tapping process in three types of cast iron. Int. J. Adv. Manuf. Technol. 2016, 82, 1041-1048. [CrossRef]

45. Ni, J.; Feng, G.; Meng, Z.; Hong, T.; Chen, Y.; Zheng, X. Reinforced lubrication of vegetable oils with graphene additive in tapping ADC12 aluminum alloy. Int. J. Adv. Manuf. Technol. 2017, 1-10. [CrossRef]

46. ASTM. ASTM D5619-00: Standard Test Method for Comparing Metal Removal Fluids Using the Tapping Torque Test Machine (Withdrawn 2016); ASTM International: West Conshohocken, PA, USA, 2011. 
47. Microtap GmbH. The TTT System-A Window into Tribology. Available online: https://www.tapping-torquetest.com/files/4914/6218/6159/TTT-System_a_Window_into_Tribology_KMM-April-2016.pdf (accessed on 10 October 2020).

48. Pottirayil, A.; Kailas, S.V.; Biswas, S.K. Lubricity of an oil in water emulsion in metal cutting: The effect of hydrophilic/lypophilic balance of emulsifiers. Colloids Surf. A Physicochem. Eng. Asp. 2011, 384, 323-330. [CrossRef]

49. Plaza, S.; Margielewski, L.; Celichowski, G.; Wesolowski, R.W.; Stanecka, R. Tribological performance of some polyoxyethylene dithiophosphate derivatives water solutions. Wear 2001, 249, 1077-1089. [CrossRef]

Publisher's Note: MDPI stays neutral with regard to jurisdictional claims in published maps and institutional affiliations.

(C) 2020 by the authors. Licensee MDPI, Basel, Switzerland. This article is an open access article distributed under the terms and conditions of the Creative Commons Attribution (CC BY) license (http://creativecommons.org/licenses/by/4.0/). 